\title{
Creative Self-Efficacy of Undergraduate Women Engineering Majors
}

\section{Dr. Christine Delahanty, Bucks County Community College}

Dr. Delahanty is the Area Coordinator of Science and Engineering, and Professor of Engineering and Physics at Bucks County Community College (Bucks). She worked as an electrical engineer at General Electric Co. for nine years in both military and commercial communication satellite operations. Her research interests include investigating creativity within STEM education as a factor in cultivating diversity. She establishes technical, college level, programs of study for modernized classroom and laboratory curricula including online course platforms, and integrated technologies. She has been involved in both private and government grants as author and project director, and is currently PI of an NSF ATE grant, "Increasing the Number of Engineering Technicians in Southeastern Pennsylvania." A major goal of this collaborative effort with Drexel University is to connect for-credit, occupational technician education to workforce development certification programs. She was the faculty advisor to two student teams that made the final round of the NSF AACC Community College Innovation Challenge (CCIC) in 2016 and 2017. She and her students have been involved in STEM related outreach to local community groups and K-12 schools.

\section{Dr. Jason Silverman, Drexel University}

Jason Silverman PhD's research interests include mathematics teacher education and supporting the pedagogical development of pre-service STEM teachers. His current work focuses on the role of mathematical understandings in teachers' instructional practice, understanding how technology, collaboration, and community can support teaching and learning, supporting teachers' integration of science, technology, engineering and mathematics (STEM), and better understanding and capitalizing on the commonalities between undergraduate and K-12 STEM education. 


\title{
Creative Self-Efficacy of Undergraduate Women Engineering Majors
}

\author{
Christine Delahanty and Jason Silverman
}

\begin{abstract}
Creative self-efficacy (CSE) was studied in connection to beliefs about creativity. CSE is one's belief in their own creative potential. The belief that creativity can improve was discussed as a "Growth Creativity Mindset" (GCM), and the belief that creativity cannot improve was discussed as a "Fixed Creativity Mindset" (FCM). Creativity within engineering has been described as crucial to the field, and as an aspect that is appealing to women engineers. Undergraduate women engineering students local to the Philadelphia area volunteered to take a survey of CSE and beliefs about creativity. Quantitative data analysis showed that an increase in GCM likely results in an increase in CSE for students with higher than average GPA. A change in CSE had no effect on FCM. Interviews were conducted with 15 survey respondents with different levels of CSE who met criteria for success in the engineering major (2.5 GPA or above and successful completion of calculus II). Synthesis of the quantitative and qualitative data revealed that interview participants had similar lived experiences that lead them to a level of success in the engineering major, but different lived experiences that distinguished them with respect to CSE level. All participants were exposed to project based learning (PBL), had strong personal influences, exhibited perseverance in overcoming struggles, and described their negative perceptions of engineering before entering the major. Participants with all levels of CSE highlighted their own creativity with respect to the performing and visual arts, before reflecting on innovation as creative. Most participants with low CSE described their lack of creativity in the arts. They also discussed being "intimidated" by negative classroom experiences more than their peers with higher levels of CSE. Those with low CSE were also exposed to more engineering centered experiences in high school, and most had a parent who worked in the profession. It is expected that this research will provide a more comprehensive understanding of CSE, perceptions of engineering as a creative field, and the educational reform needed that connects creativity to engineering in an atmosphere that welcomes diversity.
\end{abstract}

\section{Introduction}

Engineering is a creative and diverse profession integral to the sustainability of a rapidly evolving economy, and a field where the diversity and perspectives of women engineers is essential [1], [2], [3]. This study examined the creative self-efficacy (CSE) of undergraduate women engineering majors, their beliefs about creativity, how they describe themselves as creative, and their lived experiences that influenced them to choose engineering as a career path. ABET [4] highlighted the significant connection of creativity in engineering curriculum to the engineering profession. The creative aspect of engineering has been studied as a factor in the retention of women in the engineering major and in the field [1], [2], [5], [6]. Female students routinely encounter many barriers to engineering, and women engineering students face additional challenges that impede their success while in the major. The obstacles are varied and include both social and educational factors. These barriers were shown to inhibit the creativity of students, particularly females [1], [2], [7]. Studies showed that heuristic educational experiences within project based learning (PBL) requiring spatial reasoning are an integral part of engineering and engineering-centered curricula. These experiences have been shown to encourage female students to choose engineering [3], [6], [8], [9], [10]. CSE within engineering curriculum has been studied as a part of student success in engineering education, and with respect to the retention of women engineering students in the major [7], [11].

Further investigation of the relationship between engineering curricula that cultivates creativity and CSE is needed to support the emerging evidence that engineering programs as well as the pipeline into the engineering major, need significant redevelopment to benefit all students, and to increase the participation women in the profession [1], [3], [9], [10], [12]. Diversity in the 
engineering workforce is particularly important to gain new perspectives in design and problem solving, and women are still largely excluded from contributing to this lucrative profession [1], [3], [12]. There is limited research to indicate how CSE affects female students and their decision to major in engineering, and how CSE predicts the retention of women engineering students in the major. This study sought to further investigate CSE of undergraduate women engineering students, and how their beliefs about creativity and their lived experiences influenced them to choose and succeed in engineering as a major.

\section{Industry Needs}

The need for architecture and engineering occupations is expected to increase $3 \%$ over the ten-year span from 2019-2029, during which approximately 74,800 new jobs are projected to be added, predominantly in engineering [13]. Notably, the May 2019 median salary for "engineering occupations was $\$ 81,440,52 \%$ higher than the median annual wage for all occupations in the economy, which was \$39,810" [13] (p. 1). In 2017, women comprised 52\% of the college educated labor force, $29 \%$ of Science, Technology, Engineering, and Math (STEM) jobs, but only $16 \%$ of engineering jobs [14]. The number of women holding engineering positions increased from 13\% in 2009 to $16 \%$ in 2017 [14], [15]. Although the percentage of women engineers working in the field has increased, there is still a large percentage gap between men and women in the engineering profession, despite the prestige that this career path represents, the lucrative average salary, and the need for diverse perspectives [1], [2], [5]. Although percentages of freshman intending to major in engineering increased from $18.4 \%$ in 2006 to $26.9 \%$ in 2014 for males and $3.5 \%$ to $7.9 \%$ for females, the increase in the percentage of bachelor's degrees in engineering awarded to women rose only $2.5 \%$ from $18.4 \%$ in 1997 to $20.9 \%$ in 2019 [16], [17]. These percentages remained far below the graduation rates for males. Additionally, $15 \%$ of women never enter the engineering workforce resulting in a larger gender gap [3], [16].

\section{The Literature}

This research integrates existing work on supporting diversity in the engineering discipline. Specifically, we build on existing literature that examined the barriers and challenges female students have to entering, persisting and completing an engineering major. Further, we build on the notion of engineering as a creative field and the importance of understanding how engineering is a creative field. We connect this with the value of focusing on creativity within the engineering curriculum to encourage female students to enter and to succeed in the engineering major. Finally, we introduce the notion of CSE.

Female students who choose engineering. Increasing the percentages of female students in the engineering major is necessary to accommodate the growing need for a diverse population of innovative engineers in a rapidly evolving society [14]. Research suggests that fulfilling this goal begins with understanding life and educational experiences of undergraduate women engineering majors that influenced them to choose engineering as a career path. Studies showed that there were important factors that influenced female students to choose engineering. Social factors including beliefs, environment, social networks, relationships, and classroom experiences, played an important role in female students choosing engineering as a major [18], [19]. Barriers to engineering that female students experienced included social influences, such as bias from teachers or family members that it is a field for men, negative perceptions of the 
engineering profession, and gender bias in the classroom [1], [18], [19]. Deficiencies exist in both K-12 and college engineering curricula that are known to inhibit creativity and lack spatial training [8], [9], [10]. The traditional classroom that lacks open-ended engineering centered activities involving PBL and spatial reasoning, and that perpetuates a homogeneous educational environment were also seen as major factors in discouraging female students from choosing engineering [9], [10], [18].

Female students have been known to face other limitations that included lack of adequate advising in academics, lack of self-efficacy in math and spatial skills, a limited awareness of what engineering is, and lack of female mentors in the field [3], [7], [18]. These barriers were suggested as contributing to perceptions of engineering as not creative or welcoming to diverse perspectives. This in turn was seen to contribute to the lack of female students choosing engineering, completing the major, and the small percentages entering the profession [7], [12], [18]. Jones et. al. [12] sought to determine why more women do not complete the engineering major, and investigated " engineering identification" or identification within the domain of engineering, which they defined as "the extent to which an individual defines the self through a role or performance in a particular domain" [12, p. 473]. Domain identification was shown to have an impact on confidence and self-esteem within a certain domain, such as engineering, and contributed to success in the engineering major.

Creativity in engineering. According to Scott et. al. [20], creativity "involves the production of original, potentially workable, solutions to novel, ill-defined problems of relativity high complexity" [20, p. 362]. Creativity within the engineering profession is crucial for creating change, and for solving the unique problems necessary for sustainability. Cropley [2] emphasized that "the importance of creativity to engineering becomes clear. We need engineers who are equipped- both technologically and creatively- to generate solutions sparked by change" [2, p. 161]. Charyton and Merrill [5] also highlighted the need for creativity in engineering design, "The need for creativity, problem solving, and innovation is becoming a global need. A growing interest in the need and utilization of creativity in engineering design is evident" [5, $\mathrm{p}$. 145]. The industry jobs that are most appealing to women involve innovation, design, experimentation, and new advances in the field [21]. Dahle et. al. [21] suggested that, "Female engineers enjoy the aspect of using creativity to generate new ideas and iterations in solving engineering problems" [21, p.1].

The componential theory of creativity includes three important factors necessary for an individual's creative output: cognitive skills or expertise, skills in creativity, and intrinsic motivation [20], [22]. Amabile [22] indicated that the "componential framework for the creative process" includes the four stages of creative thinking in the creative process: "preparation, incubation, illumination, and verification," which is necessary for innovation [22, p. 367]. The connection of creative process to the design process is defined in the literature as the engineering design process (EDP) [1], [2], [22]. The EDP combines convergent and divergent critical thinking skills involving crucial elements and outcomes that are significant to success in industry [1] - [4]. It is the connection of the EDP to the design process that contributes to creativity and innovation in engineering design. Creativity as part of the EDP needs to be emphasized as a crucial component of the engineering profession, and embedded in courses prerequisite to and within engineering education [1] - [3], [5], [21]. 
Cropley [1] discussed the limitations of the engineering curriculum to adequately prepare students for the profession, and the importance of incorporating divergent thinking into a highly analytical curriculum. Cropley [2], Atwood and Pretz [7], Zappe et. al. [11], and Dahle et. al. [21] indicated that a curriculum focused only on mathematics and convergent thinking was damaging to the field, and that the creative facet, which is more appealing to female students than the traditional, analytical aspect, needed to be included. Creativity was shown to be lacking in engineering and engineering-centered curricula, where instructors did not reward or recognize creativity. Open-ended, engineering-centered problems involving the EDP, that cultivated creativity and divergent thinking, in an atmosphere that welcomed diverse perspectives were shown to be effective for retaining students, and to adequately prepare them for the engineering profession [2], [5], [6], [8].

Enhancement of CSE. CSE was defined by Tierney and Farmer [23] as "the belief one has the ability to produce creative outcomes" (p. 1138). CSE refers to one's own beliefs about their creativity. Beghetto [24] linked CSE to creative ability, where CSE "beliefs tap into the more subjective, self-judgements of creative ability" [24, p. 343]. CSE has been connected to an increase in intrinsic motivation, and creative performance [20], [23] - [25]. Research into the CSE of students revealed that there were challenges in the traditional STEM classroom intended to prepare students for engineering, that inhibited the growth of CSE, and there were unique challenges for women students [11], [26], [27]. Ohland et. al. [19] suggested that "women and men derive self-efficacy from different sources. Research indicated that women were known to build self-efficacy primarily through vicarious experiences and verbal persuasion, whereas men are more likely to develop self-efficacy through mastery experiences" [19, p. 245].

Enhancement of CSE through engineering-centered activities was shown to increase spatial abilities, and was found to be particularly important to female students in preparing them for STEM majors [8], [10]. The research suggested that enhancing engineering curriculum to include project-based learning (PBL) within engineering design experiences that cultivate spatial skills, increased intrinsic motivation and CSE of students, and was seen as a factor in influencing female students to enter the engineering major, and to persist and succeed in the major [11], [26], [28]. Dweck in [18] discussed the importance of a "growth mindset" as opposed to a "fixed mindset" as a factor leading to student achievement. She defined "growth mindset" as the belief that one's own abilities can improve, and "fixed mindset" as the belief that one's abilities cannot change. Claro, Paunesku, and Dweck [29] reported that students who have a growth mindset "see difficult tasks as a way to increase their abilities" and "tend to earn better grades than students who hold a fixed mindset" [29, p. 1]. Students with a fixed mindset tend to avoid stressful or difficult situations that could undermine their achievement [18], [29]. For the purposes of discussion, we applied this concept of mindset to the belief in one's potential for creative growth.

\section{Research Questions}

The following research questions framed this study: (1) What is the relationship between CSE of undergraduate women engineering students and their beliefs about creativity? (2) How do the lived experiences of undergraduate women engineering students relate to their CSE? These questions were designed to investigate the CSE of undergraduate women engineering students with respect to their beliefs about creativity, and to better understand their lived experiences in connection with their CSE. It is our expectation that a better understanding of the 
relationship between CSE, beliefs about creativity, and the lived experiences of undergraduate women engineering majors will lead to strategies for educational reform that will benefit all students, increase pathways for female students into the engineering major, and contribute to the success of women engineering.

\section{Methodology and Instrument}

A sequential explanatory mixed methods design was used for this study [30]. This twophase methodology was best suited to this research because synthesis of the quantitative survey with the themes discovered from the qualitative data analysis lead to answers to the research questions. In this sequential explanatory design, the quantitative survey was first administered to female engineering majors during Phase I. Data from the quantitative and qualitative portions were analyzed separately. Data was analyzed from the survey to help to answer the first research question, and to identify the pool of candidates to be interviewed. The data was synthesized during Phase II as part of the analysis and discussion portions of the study. The CSE Instrument (CSEI)/Beliefs about Creativity Scale (BACS), or CSEI/BACS Engineering Survey, was comprised of a CSE assessment, and a measurement of beliefs about creativity.

The validated three question CSEI instrument was used to measure the CSE of the 121 survey respondents [24], [28]. Answer choices to the three question CSEI, and the BACS, were in the form of a five-point Likert scale: "Strongly Disagree" to "Strongly Agree." A five-point Likert scale was used for purposes of ease of taking a survey on a cell phone using this scale instead of a seven-point scale. It was expected that using a five point scale would increase the probability of participation of a young college level audience, and their completion of the survey on a cell phone. The Beliefs About Creativity Scale (BACS) portion of the survey has been administered at Drexel University to assess beliefs about creativity. The survey in this study was administered in a form specific to engineering [31]. The survey was subdivided into three sections for analysis: (1) score on the CSE instrument (CSEI), (2) score on the portion of the survey that involved beliefs that creativity can improve (BACSI), or a "Growth Creativity Mindset" (GCM), and (3) score on the portion of the survey that involved beliefs that creativity cannot change (BACSC), or a "Fixed Creativity Mindset" (FCM) [18], [29]. GCM questions focused on the survey respondent's belief in their potential to increase their level of creativity. FCM questions centered around creativity as being something that is innate and cannot change, even with practice. Table 1 displays a sample of the survey questions and the category for analysis that they represented.

\section{Population}

Survey respondents included 121 undergraduate women engineering majors contacted from two participating research sites, and a professional engineering organization for women (recruitment venue), with members from colleges and universities local to Philadelphia and surrounding region. All survey respondents were between 18 and 24 years of age. Undergraduate women engineering students volunteered to complete the CSEI/BACS Engineering Survey to determine their level of CSE and their beliefs about creativity [23], [24], [27], [28]. Selected students who indicated an interest in the demographic section of the survey, and who had a 2.5 GPA or above and successful completion of calculus II, were invited to participate in a semistructured interview to describe their lived experiences that led them to choose engineering. This criteria indicated a level of success and potential for retention in the major [12]. 
Table 1. Sample Survey Questions and Respective Category for Analysis

\begin{tabular}{|c|c|}
\hline Sample Survey Question & $\begin{array}{c}\text { Category for } \\
\text { Analysis }\end{array}$ \\
\hline "I have a knack for solving problems creatively." & CSEI \\
\hline "I can always increase my level of creativity through practice." & BASCl \\
"Being creative gives me an extra edge in my engineering classes." & (GCM) \\
\hline "Some engineering students are creative, others are not. No practice can change that." & BACSC \\
\cline { 1 - 2 } "You are either creative or not. Even trying very hard, you cannot change that much." & (FCM) \\
\hline
\end{tabular}

Participants for interviews were chosen from scores on the CSEI portion of the instrument that were in the low, medium, and high CSE range (Table 2). The CSEI scores ranged from 7-15, and were separated into low (7-9), medium (10-12), and high (13-15) levels of CSE. These ranges ensured that the participants chosen for interviews represented an appropriate distribution for data collection and analysis. Table 2 shows the distribution of interview participants in comparison to the distribution of survey respondents for demographic information. Year in program is displayed as Year 1 (freshman), Year 2 (sophomore), Year 3 (junior), Year 4 (senior). The CSEI score and the demographic information for the distribution of interview participants corresponds approximately to the distribution of survey respondents, and provides a representative sample for analysis.

Table 2. CSEI Scores and Demographics of 121 Survey Respondents Selected for Interviews in Comparison to the Scores and Demographics of 15 Interview Participants

\begin{tabular}{|c|c|c|c|c|c|c|c|}
\hline \multirow{2}{*}{ Frequencies and Percentages } & \multicolumn{3}{|c|}{ CSEI Score } & \multicolumn{3}{c|}{ Year in Program } \\
\cline { 2 - 7 } & $\mathbf{L}$ & $\mathbf{M}$ & $\mathbf{H}$ & $\mathbf{1}$ & $\mathbf{2}$ & $\mathbf{3}$ & $\mathbf{4}$ \\
\hline Survey Respondents & $\mathrm{n}=15$ & $\mathrm{n}=70$ & $\mathrm{n}=36$ & $\mathrm{n}=39$ & $\mathrm{n}=28$ & $\mathrm{n}=30$ & $\mathrm{n}=24$ \\
(Total: N= 121) & $12.4 \%$ & $58.5 \%$ & $29.8 \%$ & $32.3 \%$ & $23.1 \%$ & $24.8 \%$ & $19.8 \%$ \\
\hline Interview Participants & $\mathrm{n}=5$ & $\mathrm{n}=6$ & $\mathrm{n}=4$ & $\mathrm{n}=2$ & $\mathrm{n}=3$ & $\mathrm{n}=4$ & $\mathrm{n}=6$ \\
(Total: N= 15) & $33.3 \%$ & $40 \%$ & $26.7 \%$ & $13.3 \%$ & $20 \%$ & $26.7 \%$ & $40 \%$ \\
\hline
\end{tabular}

The 15 interview participants represented $12.4 \%$ of the 121 survey respondents, and $26.3 \%$ of the 57 interested candidates for interviews. Because there were more than 15 students who met the criteria, eligible participants were first chosen based on the distribution of their CSEI scores and their availability for an interview. The final 15 participants met this eligibility criteria, and represented the demographic portion of the survey (Table 2). This selection process was chosen to add richness and depth to the study, and allowed for the most effective comparison of quantitative and qualitative portions [30]. The audio data from the interviews was 
transcribed and analyzed for codes and emerging themes (see Table 3). Table 3 lists the 15 participants interviewed, their label for discussion that indicated their CSE level from the CSEI portion of the survey (L: Low $(n=5)$, M: Medium $(n=6), H$ : High $(n=4)$ ), and a number that specified the order in which they were interviewed. The labels of Low, Medium, and High referenced the score on the CSEI portion of the survey and did not reflect the analysis.

Table 3. CSE Level and Demographic Information For 15 Interview Participants.

\begin{tabular}{|c|c|c|c|c|}
\hline $\begin{array}{c}\text { Level of Creative Self- } \\
\text { Efficacy (CSE) (N=15) }\end{array}$ & $\begin{array}{c}\text { Label for } \\
\text { Discussion }\end{array}$ & $\begin{array}{c}\text { CSEI Level } \\
\text { Range: 7-15 }\end{array}$ & $\begin{array}{c}\text { GPA Range } \\
(>2.5)\end{array}$ & $\begin{array}{c}\text { Year in } \\
\text { Program }\end{array}$ \\
\hline \multirow{4}{*}{$\begin{array}{c}\text { Low } \\
\text { (CSEI score of 7-9) } \\
\text { (n=5) }\end{array}$} & L4 & Low (7) & $2.5-2.49$ & Sophomore \\
\cline { 2 - 5 } & L7 & Low (8) & $3.0-3.49$ & Sophomore \\
\cline { 2 - 5 } & L9 & Low (9) & $3.5-3.99$ & Freshman \\
\cline { 2 - 5 } & L11 & Low (7) & $3.5-3.99$ & Senior \\
\cline { 2 - 5 } & L14 & Low (8) & $3.5-3.99$ & Senior \\
\hline \multirow{4}{*}{$\begin{array}{c}\text { Medium } \\
\text { (CSEI score of 10-12) } \\
\text { (n=6) }\end{array}$} & M3 & Medium (12) & $2.5-2.99$ & Sophomore \\
\cline { 2 - 5 } & M5 & Medium (12) & $3.0-3.49$ & Senior \\
\cline { 2 - 5 } & M8 & Medium (11) & $3.5-3.99$ & Senior \\
\cline { 2 - 5 } & M10 & Medium (12) & $3.0-3.49$ & Senior \\
\cline { 2 - 5 } & M12 & Medium (11) & $3.5-3.99$ & Junior \\
\cline { 2 - 5 } & M15 & Medium (12) & $3.5-3.99$ & Senior \\
\hline \multirow{4}{*}{$\begin{array}{c}\text { High } \\
\text { (CSEI score of 13-15) } \\
(n=4)\end{array}$} & H1 & High (15) & $3.5-3.99$ & Junior \\
\cline { 2 - 5 } & H2 & High (14) & $3.0-3.49$ & Junior \\
\cline { 2 - 5 } & $\mathrm{H} 6$ & High (15) & $3.0-3.49$ & Junior \\
\cline { 2 - 5 } & $\mathrm{H} 13$ & High (13) & 4.0 & Freshman \\
\hline
\end{tabular}

\section{Quantitative Findings}

Quantitative data analysis provided insight to help answer the first research question: "What is the relationship between CSE of undergraduate women engineering students and their beliefs about creativity?" The quantitative analysis of the survey data collected consisted of demographic information, descriptive statistics (Tables, 4, 5, 6), and significance levels for correlations and regression analysis (Table 7). Demographic Information on student achievement revealed that the sample of survey respondents was not typical, where $83.5 \%(n=101)$ had a GPA of 3.0 or higher, and $51 \%(n=62)$ had a GPA of 3.5 or higher (Table 4$)$. There were $83.5 \%$ $(n=101)$ of survey respondents who reported that they had successfully completed calculus II, which indicated a level of mathematical advancement in the major. A one sample t-test was performed at the $\mathrm{p}=0.01$ level $(1 \%$ chance that the occurrence was random $)$. The result, $\mathrm{t}(120)=$ $13.059, \mathrm{p}=0.000<0.01$, revealed that the scaled mean CSEI score of survey respondents of 5.57 (S.D. $=1.811, \mathrm{~N}=121$ ), was significantly different than the population mean of 3.42 (S.D. = 0.93, $\mathrm{N}=1,322$ ) (see Table 4) [24]. This meant that the mean CSE level of the undergraduate 
women engineering majors who elected to complete the survey was significantly higher than the population as was reported by Beghetto [24] in his study.

Table 4. Frequency data for GPA and Year in Program of Survey Respondents

\begin{tabular}{c|cc} 
GPA & Freq & $\%$ \\
\hline $0.0-1.99$ & 1 & .8 \\
\hline $2.00-2.49$ & 6 & 5.0 \\
\hline $2.50-2.99$ & 13 & 10.7 \\
\hline $3.0-3.49$ & 39 & 32.2 \\
\hline $3.5-3.99$ & 56 & 46.3 \\
\hline 4.00 & 6 & 5.0 \\
\hline Total & 121 & 100.0
\end{tabular}

\begin{tabular}{c|c|c}
$\begin{array}{c}\text { Year in } \\
\text { Program }\end{array}$ & Freq & $\%$ \\
\hline Freshman & 39 & 32.2 \\
\hline Sophomore & 28 & 23.1 \\
\hline Junior & 30 & 24.8 \\
\hline Senior & 24 & 19.8 \\
\hline Total & 121 & 100
\end{tabular}

Frequency data for CSEI, BACSC, and BACSI scores in Table 5, and skewness data in Table 6, show that there is a slightly larger number of survey respondents who had stronger GCM (BACSI score). There was a slightly smaller number of survey respondents who had stronger FCM (BACSC score). The survey respondents were more likely to have a GCM, or a "growth mindset" with respect to creativity, and slightly less likely to have an FCM, or a "fixed mindset" with respect to creativity [29].

Table 5. Frequencies of CSEI, BACSI, and BACSC Scores

\begin{tabular}{c|cc}
$\begin{array}{c}\text { CSEl } \\
\text { Score }\end{array}$ & Freq & $\%$ \\
\hline 7 & 5 & 4.1 \\
\hline 8 & 4 & 3.3 \\
\hline 9 & 6 & 5.0 \\
\hline 10 & 15 & 12.4 \\
\hline 11 & 16 & 13.2 \\
\hline 12 & 39 & 32.2 \\
\hline 13 & 24 & 19.8 \\
\hline 14 & 7 & 5.8 \\
\hline 15 & 5 & 4.1 \\
\hline Total & 121 & 100.0
\end{tabular}

\begin{tabular}{c|c|c|}
$\begin{array}{c}\text { BACSI } \\
\text { Score }\end{array}$ & Freq & $\%$ \\
\hline 19 & 1 & .8 \\
\hline 21 & 1 & .8 \\
\hline 22 & 2 & 1.7 \\
\hline 23 & 3 & 2.5 \\
\hline 24 & 3 & 2.5 \\
\hline 25 & 7 & 5.8 \\
\hline 26 & 9 & 7.4 \\
\hline 27 & 15 & 12.4 \\
\hline 28 & 15 & 12.4 \\
\hline 29 & 17 & 14.0 \\
\hline 30 & 10 & 8.3 \\
\hline 31 & 18 & 14.9 \\
\hline 32 & 8 & 6.6 \\
\hline 33 & 8 & 6.6 \\
\hline 34 & 1 & .8 \\
\hline 35 & 3 & 2.5 \\
\hline Total & 121 & 100.0 \\
\hline
\end{tabular}

\begin{tabular}{c|c|c|}
$\begin{array}{c}\text { BACSC } \\
\text { Score }\end{array}$ & Freq & $\%$ \\
\hline 6 & 3 & 2.5 \\
\hline 7 & 4 & 3.3 \\
\hline 8 & 9 & 7.4 \\
\hline 9 & 12 & 9.9 \\
\hline 10 & 17 & 14.0 \\
\hline 11 & 16 & 13.2 \\
\hline 12 & 24 & 19.8 \\
\hline 13 & 13 & 10.7 \\
\hline 14 & 7 & 5.8 \\
\hline 15 & 5 & 4.1 \\
\hline 16 & 9 & 7.4 \\
\hline 17 & 1 & .8 \\
\hline 18 & 1 & .8 \\
\hline Total & 121 & 100.0 \\
\hline
\end{tabular}


Table 6. Descriptive Statistics from BACS/CSEI Survey

\begin{tabular}{|l|c|c|c|c|}
\hline \multicolumn{5}{|c|}{ Descriptive Statistics for 121 Survey Respondents } \\
\hline \multicolumn{2}{|c|}{ Statistic } & $\begin{array}{c}\text { CSEI Score } \\
\text { (Range: 7-9) }\end{array}$ & $\begin{array}{c}\text { BACSI Score (GCM) } \\
\text { (Range: 19-35) }\end{array}$ & $\begin{array}{c}\text { BACSC Score (FCM) } \\
\text { (Range: 6-18) }\end{array}$ \\
\hline \multirow{2}{*}{$\mathrm{N}$} & Valid & 121 & 121 & 121 \\
\cline { 2 - 5 } & Missing & 0 & 0 & 0 \\
\hline Mean & 11.57 & 28.67 & 11.41 \\
\hline Median & 12.00 & 29.00 & 11.00 \\
\hline Std. Deviation & 1.811 & 3.048 & 2.571 \\
\hline Variance & 3.280 & 9.290 & 6.611 \\
\hline Skewness & -.637 & -.384 & .170 \\
\hline Minimum & 7 & 19 & 6 \\
\hline Maximum & 15 & 35 & 18 \\
\hline Scaled mean & 5.57 & & \\
\hline Scaled Minimum & & 1 & & \\
\hline
\end{tabular}

*Scaled mean was used in one sample t-test for comparison to reported population mean [24].

The correlations and regression analysis of CSE versus GCM (CSEI score vs BACSI score), and CSE versus FCM (CSEI score vs BACSC score) are presented in Table 7. Since the distributions of the CSEI, BACSI, and BACSC scores were approximately symmetrical (normally distributed), the Pearson correlation, $\beta$ applied for analysis. The analysis of variance (ANOVA) for a two-tailed F-test test was performed to test for significance of the relationships between the variables at the $p=0.05$ level. Correlations revealed that there was a significant positive correlation at the $\mathrm{p}=0.05$ level (two-tailed) between the BACSI score and CSEI score where the Pearson correlation was $\beta=0.225$, and $\mathrm{F}(1,6.324)=0.013<0.05$. Since 0.013 was less than the significance level of $\mathrm{p}=0.05$, this test revealed an association between GCM (BACSI score), and CSE level (CSEI score). The data revealed that there was no significant correlation between CSE and FCM (CSEI score vs BACSC score), where $\mathrm{F}(1,0.027)=0.869$ > 0.05 . Since 0.869 was greater than the significance level of 0.05 , this meant that stronger FCM (BACSC score) had no effect on CSE level.

Regression analysis showed that there was a significant positive linear relationship between CSEI score and BACSI score $(\beta=0.225, \mathrm{t}=2.593$, sig. $=0.011<0.05)$. This meant that a gain in GCM would likely result in a gain in CSE level (see Figure 1). Regression analysis showed that there was no significant linear relationship between CSEI score and BACSC score $(\beta=0.05, \mathrm{t}=0.675$, sig. $=0.501>0.05)$. The data showed that a gain in FCM would not necessarily result in a gain or loss of CSE (see Figure 1). Thus, CSE level was significantly positively correlated to GCM, but not correlated to FCM. This suggests that although survey respondents believed that creativity could improve, there was uncertainty with respect to creativity being innate and unchanging. 
Table 7. Correlation and Regression Analysis of CSEI vs BACSI score (GCM) and CSEI vs BACSC Score (FCM) for 121 Survey Respondents

\begin{tabular}{|c|c|c|}
\hline \multicolumn{2}{|c|}{$\begin{array}{l}\text { Correlations and Regression Analysis of } \\
\text { CSEI vs BACSI, and CSEI vs BACSC Scores for } 121 \text { Survey Respondents }\end{array}$} & $\begin{array}{l}\text { CSEI (Creative Self-Efficacy) } \\
\text { Score }\end{array}$ \\
\hline \multirow[b]{2}{*}{ BACSI Score or GCM } & Pearson Correlation $(\beta)$ & $.225^{\star}$ \\
\hline & ANOVA: F Change (d.f. = 1) & 6.324 \\
\hline \multirow{4}{*}{$\begin{array}{l}\text { (Beliefs that } \\
\text { Creativity can Improve, or Growth in } \\
\text { Creativity Mindset) }\end{array}$} & Sig. (2-tailed at $\alpha=0.05$ Level) & $.013^{\star}$ \\
\hline & Comparison of Means: $t$ value & 2.593 \\
\hline & Sig. (2-tailed at $\alpha=0.05$ Level) & $.011^{*}$ \\
\hline & $\mathbf{N}$ & 121 \\
\hline \multirow{6}{*}{ BACSC Score or FCM } & Pearson Correlation $(\beta)$ & .015 \\
\hline & ANOVA: F Change (d.f. = 1) & .027 \\
\hline & Sig. (2-tailed at $\alpha=0.05$ Level) & .869 \\
\hline & Comparison of Means: $t$ value & .675 \\
\hline & Sig. (2-tailed at $\alpha=0.05$ Level) & .501 \\
\hline & $\mathbf{N}$ & 121 \\
\hline
\end{tabular}

*Indicates significance at the $\mathbf{0 . 0 5}$ level (two-tailed)
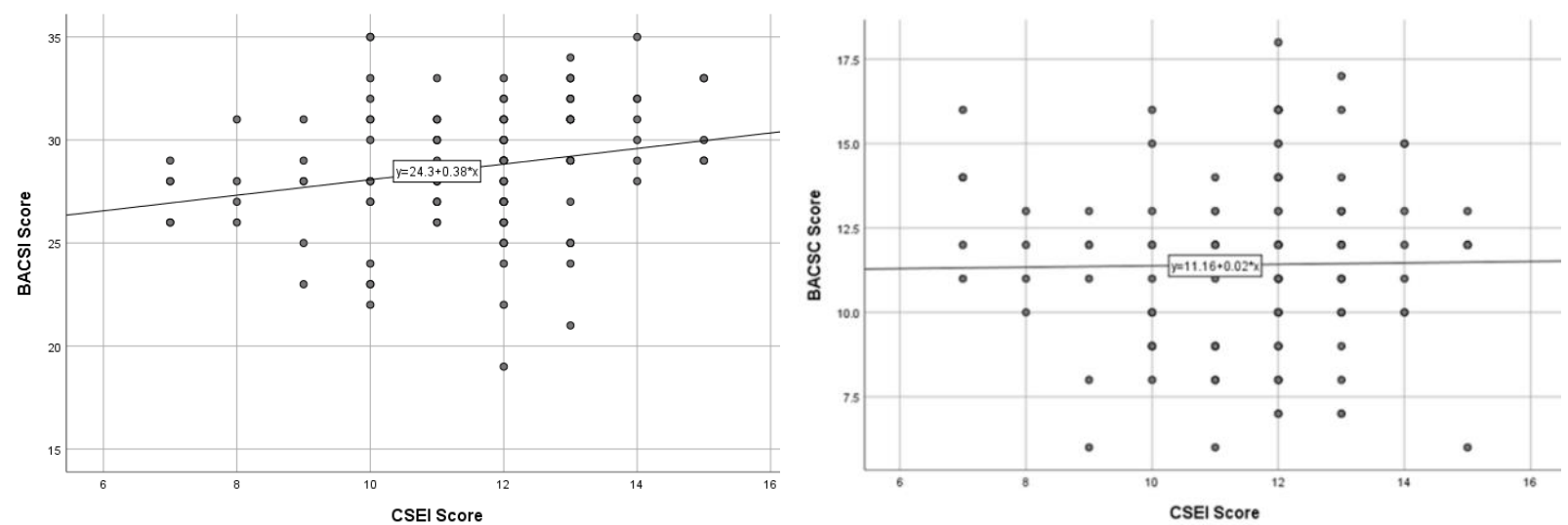

Figure 1. Scatter plots of CSEI vs BACSI (GCM), and CSEI vs BACSC (FCM) scores.

There were five key findings from the quantitative data: (1) undergraduate women engineering students who were high achieving in the engineering major with respect to GPA and level of mathematical success, were more likely to elect to participate in this study; (2) survey respondents were more likely to have a higher CSE level than the population; (3) survey respondents were more likely to have the GCM, and less likely to have the FCM; (4) the significant positive correlation between CSEI score and BACSI score meant that an increase in GCM would likely result in an increase in CSE level; (5) stronger FCM had no effect on CSE level, meaning that there was uncertainty with respect to one's creativity as something that can change [22], [28], [29]. 


\section{Qualitative Findings}

Four major themes emerged from the qualitative data analysis that provided insight to help answer the research questions: (1) Pathways into Engineering, (2) Breaking Barriers to Engineering as a Major, (3) Success as an Engineering Student, (4) Overcoming Challenges in the Engineering Major. Table 8 lists the four major themes and 17 subthemes that were derived from the qualitative analysis. Synthesis of the quantitative and qualitative findings helped to answer the second research question, "How do the lived experiences of undergraduate women engineering students relate to their CSE?" For the purposes of this research, we present a more detailed analysis of the qualitative findings depicted in Table 8. For discussion, $\mathrm{N}$ refers to the entire sample of interview participants, and n refers to low, medium and high levels of CSE.

Theme 1: Pathways into engineering. All (100\%, N=15) participants recounted having success in traditional math and science courses in K-12 that were prerequisites to the engineering major. Sixty seven percent $(67 \%, \mathrm{~N}=10)$ of participants took engineering-centered elective courses in high school, and $100 \%(\mathrm{n}=5)$ had a low level of CSE. Elective courses included coding, computer aided design (CAD), and pre-engineering courses involving PBL utilizing the EDP. A notable difference between groups was that $60 \%(n=3)$ of participants in the low CSE group described extra-curricular STEM based clubs or teams in high school, in contrast to $17 \%$ $(n=1)$ in the medium group, and $25 \%(n=1)$ in the high group. L4 discussed her experiences with two engineering design courses involving computer aided design (CAD), and reflected on how those courses influenced her, "if I didn't have that experience of those just two, like intro courses, I would not have been confident enough to go into engineering." L7 recalled, "Like my junior year, I joined my high school's robotics team and I think that very much like shaped me being more like me wanting to be an engineer." All participants $(100 \%, \mathrm{~N}=15)$ discussed mentors and role models who supported them, and who influenced them to choose engineering. Participants reflected on regaining confidence in their abilities through these personal interactions.

Mentors and role models raised awareness of engineering as a career option that influenced the female students to choose engineering as a major. M10 recounted the support and nurturing she received from her father who spent time with her doing engineering-centered activities, "He [dad] was always really encouraging... So that was like part of the reason why I wanted to choose to do engineering." H13 reflected on the support she received from her mother who was an engineer." My mom, who is an engineer herself, was always just excited about getting me involved and like seeing her daughters sort of like pursue those, like, interests." Fifty three $(53 \%, \mathrm{~N}=8)$ of all participants had a family member who worked in the engineering profession. Eighty percent $(80 \%, n=4)$ of participants with low CSE indicated that they had a family member in the field, in contrast to $50 \%(\mathrm{n}=3)$ in the medium group, and $25 \%(\mathrm{n}=1)$ in the high group. These differences distinguished those participants with low CSE. Some participants with low CSE reflected on their parent's skepticism with respect to their choice of engineering as a major, "I think they're just like very worried about me just because that's unconventional....'I don't know if that's for you,' but he [dad] wasn't like against it or anything" (L7). Participants with low CSE highlighted encouragement from teachers and coaches, "I think my computer science teacher was really, really influential with it. He really pushed engineering, especially for girls, because like, that's not something that girls are a big part of" (L7). 
Table 8. Summary of Interview Responses from the Four Themes, and Subthemes

\begin{tabular}{|c|c|c|c|c|}
\hline \multirow{2}{*}{$\begin{array}{l}\text { Themes and Subthemes Derived from } \\
\text { Qualitative Analysis of the Interviews }\end{array}$} & \multicolumn{3}{|c|}{ Participant CSE Levels* } & \multirow{2}{*}{$\begin{array}{l}\text { Totals* } \\
(\mathrm{N}=15)\end{array}$} \\
\hline & Low $(n=5)$ & Medium ( $n=6)$ & High $(n=4)$ & \\
\hline \multicolumn{5}{|c|}{ Theme 1: Pathways into Engineering } \\
\hline Exposed to project based learning & $100 \%(n=5)$ & $100 \%(n=6)$ & $100 \%(n=4)$ & $100 \%(\mathrm{~N}=15)$ \\
\hline Took elective engineering-centered courses & $100 \%(n=5)$ & $50 \%(n=3)$ & $50 \%(n=2)$ & $67 \%(N=10)$ \\
\hline Extra-curricular high school STEM activities & $60 \%(n=3)$ & $17 \%(n=1)$ & $25 \%(n=1)$ & $33 \%(\mathrm{~N}=5)$ \\
\hline Other activities that encouraged engineering & $80 \%(n=4)$ & $67 \%(n=4)$ & $50 \%(n=2)$ & $67 \%(\mathrm{~N}=10)$ \\
\hline Discussed mentors and role models & $100 \%(n=5)$ & $100 \%(n=6)$ & $100 \%(n=4)$ & $100 \%(\mathrm{~N}=15)$ \\
\hline Family member who worked in engineering & $80 \%(n=4)$ & $50 \%(n=3)$ & $25 \%(n=1)$ & $53 \%(\mathrm{~N}=8)$ \\
\hline \multicolumn{5}{|c|}{ Theme 2: Breaking Barriers Engineering as a Major } \\
\hline Discussed breaking barriers & $80 \%(n=4)$ & $50 \%(n=3)$ & $75 \%(n=3)$ & $67 \%(N=10)$ \\
\hline Traditional K-12 classroom & $80 \%(n=4)$ & $50 \%(n=3)$ & $50 \%(n=2)$ & $60 \%(N=9)$ \\
\hline Negative perceptions of engineering & $80 \%(n=4)$ & $83 \%(n=5)$ & $75 \%(n=3)$ & $80 \%(\mathrm{~N}=12)$ \\
\hline \multicolumn{5}{|c|}{ Theme 3: Success as an Engineering Student } \\
\hline Described own creativity within "artistic" talent & $80 \%(n=4)$ & $83 \%(n=5)$ & $75 \%(n=3)$ & $80 \%(N=12)$ \\
\hline Described own creativity as ideas or innovation & $40 \%(n=2)$ & $83 \%(n=5)$ & $100 \%(n=4)$ & $73 \%(\mathrm{~N}=11)$ \\
\hline Detailed an artistic talent within creativity & $0 \%(n=0)$ & $83 \%(n=5)$ & $100 \%(n=4)$ & $60 \%(N=9)$ \\
\hline Able to describe engineering as creative & $100 \%(n=5)$ & $67 \%(n=4)$ & $100 \%(n=4)$ & $87 \%(\mathrm{~N}=13)$ \\
\hline Creativity in engineering design experiences & $60 \%(n=3)$ & $83 \%(n=5)$ & $75 \%(n=3)$ & $73 \%(\mathrm{~N}=11)$ \\
\hline Importance of female support networks & $80 \%(n=4)$ & $83 \%(n=5)$ & $50 \%(n=2)$ & $73 \%(\mathrm{~N}=11)$ \\
\hline \multicolumn{5}{|c|}{ Theme 4: Overcoming Challenges in the Engineering Major } \\
\hline Discussed how they overcame challenges & $100 \%(n=5)$ & $83 \%(n=5)$ & $100 \%(n=4)$ & $93 \%(N=14)$ \\
\hline Discussed gender-related issues & $100 \%(n=5)$ & $67 \%(n=4)$ & $50 \%(n=2)$ & $73 \%(N=11)$ \\
\hline Traditional engineering classroom lacking design & $20 \%(n=1)$ & $40 \%(n=2)$ & $75 \%(n=3)$ & $40 \%(N=6)$ \\
\hline
\end{tabular}

${ }^{*} \mathbf{n}$ refers to low, medium, and high CSE levels, and $\mathbf{N}$ refers to entire sample of interview participants

Theme 2: Breaking barriers to engineering. Participants at all levels of CSE described personal growth, and an increase in self-awareness that was shaped by intrinsic and extrinsic motivation [20], [22]. Overcoming a lack of confidence, intimidation, and academic struggles through perseverance (intrinsic), and support from role models (extrinsic) were major factors in helping participants break barriers to engineering. L4 described how concepts didn't come easy to her, "I just tend to work harder, but I had to work harder because I didn't come this natural to me as it would come to them" (L4). M5 struggled greatly in her calculus course and overcame that as a barrier, "I started working really hard... I liked putting in hard work and seeing that I can, I can get smarter and I can learn things if I put my mind to it" (M5). Barriers included the traditional male dominated STEM classroom. M5 went on to describe challenges in a male dominated classroom that included both high school and her college experience, "I'm kind of left on my own. I don't really get a partner. So, yeah, I would say that's my biggest barrier" (M5). Although they were able to describe engineering as creative once they had entered the major, $80 \%(\mathrm{~N}=12)$ of all participants interviewed indicated that in their $\mathrm{K}-12$ experience, they did not know what engineering was until someone enlightened them to engineering as a career choice. 
Eighty percent $(80 \%, \mathrm{~N}=12)$ of all participants described negative perceptions of engineering before they entered the major, regardless of whether they had a family member working in the profession. "I just thought of it as more just math, science, kind of very nerdy and logical" (M3). "I really didn't know much about it or what it entailed. It sounded kind of dorky to me... I pictured engineers as guys and like hardhats and construction vests... I didn't really see myself doing that" (H1). "It's really intimidating to me, this word engineering. It is only the really intelligent people doing it, right? A lot of math" (H2). L9 discussed gender in her initial view of the engineer, and expressed her fear of being in a room "filled with a bunch of guys who wouldn't talk to me"... "the big nerds, you know, like the geeky guys who don't know how to talk to people and aren't creative" (L9). M8 reflected on her limited view of engineering, "I think my understanding of what engineering was, was kind of like, oh, construction worker, like the person that designs things...." (M8).

Theme 3: Success as an engineering student. All interview participants demonstrated a level of success in the engineering major and identified with the major [12]. Participants with all levels of CSE were able to describe engineering as creative after they had entered college and experienced the engineering major $(87 \%, \mathrm{~N}=13)$. Eighty seven percent $(73 \%, \mathrm{~N}=11)$ reflected on positive, creative design experiences in college. "I say engineering is creative because it allows you to apply the knowledge that you have in ways that are innovative, in ways that can make changes that you want to see in the world" (H13). When asked to describe themselves as creative, $80 \%(\mathrm{~N}=12)$ reflected on artistic talent as a primary measure of creativity, and $73 \%$ $(\mathrm{N}=11)$ referenced innovation. However, only $40 \%(\mathrm{n}=2)$ with low CSE mentioned innovation, in contrast to $83 \%(n=5)$ and $100 \%(n=4)$ for those with medium and high CSE respectively. Participants with higher CSE highlighted their enjoyment of the arts such as dance, drawing, painting, music and design, before referencing themselves as innovative. "I did a lot with like music and performing arts. I like that aspect of creativity, more like an artistic way. But I'm a big problem solver and I always like to find a different way to solve things" (H1). "I like to think I'm a very creative person. I've, I've always been artistic my whole life..." (M12). Participants with higher CSE referenced innovation after they reflected on their artistic talents. Participants with low CSE distinguished themselves from those participants with medium and high CSE levels in how they described themselves as creative. Most of the participants with low CSE described themselves as not having artistic talent, and none of them highlighted that they had a talent in the arts. "I would not think of myself as that creative, which I guess is not very good in this field. I guess I don't really do like that much artsy stuff...." (L7). Another participant with low CSE expressed her belief about creativity as being connected to art, "I think a lot of creativity in general is kind of associated with art. So as like I've always been a math and academic person, so I've never really viewed myself as creative" (L11).

Seventy three percent $(73 \%, \mathrm{~N}=11)$ of all participants reflected on support from gender specific social networks. Eighty percent $(80 \%, n=4)$ were in the low CSE group, $83 \%(n=5)$ were in the medium group. The high CSE group had the lowest number of participants who described female support networks, where $50 \%(n=2)$ in this group described such experiences. Many participants reflected on the importance of networks for encouragement and coping. The women engineering majors discussed seeking out female support groups that became a significant source of comfort through difficult aspects of the program, including coping with gender-related issues. Participants with low and medium CSE reflected more on support from female peers to help 
them cope in the engineering major, "So, I have a strong, good, strong core of female engineering friends and they're like different disciplines. But we all kind of work together when we have opportunities to. I think just kind of sticking to, you know, someone who kind of relates to your experience and it kind of helps you push forward" (L14).

Theme 4: Overcoming challenges as an engineering major. Ninety three percent (93\%, $\mathrm{N}=14)$ of all participants described overcoming challenges to reach a level of success in the engineering major. Participants with all levels of CSE described challenges with the level of difficulty of the major, traditional engineering curriculum, and with gender bias. Participants with all levels of CSE discussed perseverance and coping as factors in their success in the major. "You have to keep pushing so, on difficulty, respecting you academically, or in terms of atmosphere. OK, so academically it's, it's, it's extremely difficult" (H2). H6 reflected on sacrificing a social atmosphere "I think it definitely requires a lot of sacrifice, a lot of just understanding that it's gonna be four years of what other people probably consider hell; it will be worth it in the end" (H6). Participants with the highest CSE emphasized issues they had with the traditional college engineering curriculum not welcoming creativity. "It's kind of hard to be creative in school because every problem we're given of some structure ... And then once you're thrown into design, it's like you have a hard time knowing where you're supposed to start" (H2).

Themes 2 and 4 revealed that the traditional classroom presented a challenge for all participants in both K-12 and in college. Participants with the lowest CSE recounted the structured traditional classroom prior to high school that did not include much PBL, and reflected on being "intimidated" by male students in high school and in college. L4 described her challenges with male students, "And so, I was a lot of I was just scared because a lot of guys intimidated me and liked to show off and try to prove to you that they are better than you and they were smarter than you. And I'm a very let's work together type of person versus I can do this better than you" (L4). This intimidation extended to feelings of isolation as a woman in the engineering major. "I guess that like all of the faculty is like male. I don't know. It's just... like it's different, I guess, because like sometimes you have questions and like, you don't understand stuff, but you don't want to go to their office alone and ask questions. I don't know. Maybe this me, but..." (L7). Participants with higher CSE reflected on their attempts to correct the situation, and on fighting back. "I'll be in classes where we have to do projects and, you know, like boys my age who I'm working with, don't take me seriously, don't really acknowledge my ideas at times like I've experienced that where I have to, like, fight and push. And then like a lot of times I'm right" (H1).

Notable distinctions between participants with different CSE levels from the qualitative analysis. There were the five notable distinctions between participants with low CSE and the those with medium and high CSE: (1) All (100\%, n=5) participants with low CSE revealed that they took elective engineering-centered courses in high school, in contrast to $50 \%$ of participants with both medium CSE $(n=3)$ and high CSE $(n=2)$ who discussed taking these courses in high school; (2) sixty percent $(60 \%, n=5)$ of participants with low CSE participated in high school STEM based clubs or teams, in contrast to $17 \%(\mathrm{n}=1)$ of participants with medium CSE and $25 \%(n=1)$ of participants with high CSE; (3) eighty percent $(80 \%, n=5)$ of participants with low CSE revealed that that had a family member who worked in the engineering profession in contrast to $50 \%(n=3)$ of those with medium CSE, and $25 \%(n=1)$ of those with high CSE; (4) 
when asked to describe themselves as creative, none of the participants with low CSE highlighted having an artistic talent or interest when asked about their own creativity. Eighty percent $(80 \%, n=4)$ of participants with low CSE described themselves as not creative, and referenced the arts. Eighty three percent $(83 \%, n=5)$ of participants with medium CSE, and $100 \%$ $(n=4)$ with high CSE recounted a talent or interest in the arts. Forty percent $(40 \%, n=4)$ of participants with low CSE described their creativity as ideas or innovation, in contrast to 83\% $(\mathrm{n}=5)$ and $100 \%(\mathrm{n}=4)$ of participants with medium and high CSE respectively; (5) All 100\% $(n=5)$ of the participants with low CSE, recounted gender bias within either their K-12 experience, or within the engineering major, involving male students or professors.

There were two notable distinctions between participants with high CSE and those with lower levels of CSE: (1) fewer participants with high CSE reflected on female support networks, where $50 \%(n=2)$ of members with high CSE recounted support from female networks in contrast to $80 \%(n=4)$ for participants with low CSE, and $83 \%(n=5)$ for participants with medium CSE; (2) seventy five percent $(75 \%, n=3)$ of participants with high CSE discussed the traditional college engineering curriculum that lacked in engineering design, in contrast to $20 \%$ $(n=1)$ for participants with low CSE, and $40 \%(n=2)$ for participants with medium CSE.

\section{Discussion}

In this section we provide a synthesis of the key quantitative and qualitative findings in connection to the literature.

The relationship between CSE of undergraduate women engineering students and their beliefs about creativity. In this study, we found a relationship between CSE and the belief that creativity can improve (BACSI), or GCM. CSE of the undergraduate women engineering majors who took the CSEI/BACS Engineering Survey, was positively correlated to GCM. This means that stronger beliefs that creativity can improve with practice would likely result in a higher CSE level (Table 7 and Figure 1) [29]. An increase in CSE was associated with an improvement in creative performance, and an increase in intrinsic motivation [22], [28]. Tierney and Farmer [28] reported that "creative self-efficacy was positively and significantly related to creative performance," and that confidence in creative abilities played a role [28, p. 1144]. This relates to GCM vs FCM and confidence in creative abilities [18], [29]. If a person's GCM increases, this is likely to result in an increase in their CSE. The significant positive correlation between CSE and GCM indicated that CSE was a predictor of GCM, and this was consistent with the literature [18], [23], [26], [28], [29]. In this study, there was no significant relationship between CSE and beliefs that creativity cannot improve (BACSC), or FCM. Quantitative analysis showed that a stronger FCM would not necessarily result in higher or lower level of CSE (see Table 7 and Figure 1). This is an area that needs further investigation.

The relationship between lived experiences of undergraduate women engineering students and their CSE. Synthesis of quantitative and qualitative findings indicated that there was a connection between how a participant described themselves as creative and their level of CSE. All participants achieved a level of success in the engineering major, and reflected on perseverance, and personal influences as factors contributing to their success. All had been exposed to PBL at some point in their K-12 experience. However, lived experiences of the undergraduate women engineering students that related to low CSE level included perceptions of 
themselves as not creative within the arts, or as innovative. They also discussed issues with the traditional classroom, that included gender bias, isolation, and intimidation by male students and faculty. Participants with low CSE were exposed to fewer experiences with PBL prior to high school, and to a greater number of sought out engineering-centered courses and STEM related activities involving PBL in high school. More participants with low CSE had a family member who worked in the field, and they also sought out support from female peers in college [18]. Most of the participants with the highest level of CSE described issues in college engineering courses that did not effectively introduce or include engineering design. Participants with high CSE who already expressed a talent in the arts and reflected a confidence in themselves as creative with respect to art and innovation, also recounted frustration that the engineering curriculum did not cultivate their artistic interests. This was consistent with challenges involving the traditional engineering classroom that does not recognize or reward creativity [1], [2], [7], [8]. Participants with high CSE recounted less support from female social networks. Participants with higher CSE discussed solutions to issues with gender bias such as "fighting back" and exercising leadership, in contrast to those with low CSE who referenced intimidation, fear, and isolation. Results from this study showed that there was a connection between a participant's confidence in themselves as creative as artistic and innovative, and exhibiting leadership in dealing with adverse classroom situations.

\section{Conclusions}

The results of this study lead to the following conclusions: (1) an increase in GCM likely results in an increase in CSE for women engineering students with higher than average GPA, and who identify with the engineering major by achieving a level of success in the major [12]; (2) Undergraduate women engineering students who are successful in the major are more likely to have a GCM than an FCM. (3) Change in CSE has no effect on FCM; (4) Defining creativity in terms of artistic talent was a factor related to CSE level; (5) interview participants had negative perceptions of engineering before entering the major that it was gender based and not creative; (6) lived experiences inside and outside of the classroom, perseverance, and personal influences contributed to the CSE level of the women engineering students interviewed.

\section{Future Research}

The results and conclusions of this study indicated the need for further research. Future research includes: (1) further analyzing the interviews within the results of this study; (2) extending this study to include a larger sample of undergraduate women engineering students to further explore the connection between CSE, beliefs about creativity, and descriptions of themselves as creative, in relation to lived experiences; (3) conducting a longitudinal study of undergraduate women engineering students to better understand how their CSE may change as they progress through their engineering program, and (4) extending this study to a wider audience to better understand CSE and perspectives of women engineering students of all cultural backgrounds, male engineering students, engineering professors, K-12 teachers, and women engineers in the profession. The goal of this future research is to better understand why only approximately $20 \%$ of engineering graduates are women, why there are only $16 \%$ of engineers in the workforce are women, and why up to $40 \%$ of women engineers leave the workforce within ten years [14], [16], [17]. The intention of this research is to build upon this current study and the literature, to address a wider, more diverse population for the purposes of reforming education for all students. 


\section{References}

[1] Cropley, D. H. (2015a). Creativity in engineering: Novel solutions to complex problems. London; San Diego, CA: Academic Press, an imprint of Elsevier.

[2] Cropley, D. H. (2015b). Promoting creativity and innovation in engineering education. Psychology of Aesthetics, Creativity, and the Arts, 9(2), 161-171. doi:10.1037/aca0000008

[3] Dahle, R., Eagleston, K., \& Jockers, L. (2017a). Bridging the gap between academia and industry to reduce female attrition from engineering. 2017 IEEE Women in Engineering (WIE) Forum USA East. doi:10.1109/WIE.2017.8285612

[4] Accreditation Board of Engineering and Technology (ABET) engineering accreditation commission: Criteria for accrediting engineering programs. (2020). Retrieved from https://www.abet.org/wpcontent/uploads/2020/03/E001-20-21-EAC-Criteria-Mark-Up-11-24-19-Updated.pdf

[5] Charyton, C., \& Merrill, J. A. (2009). Assessing general creativity and creative engineering design in first year engineering students. Journal of Engineering Education, 98(2), 145-156. doi:10.1002/j.2168-

9830.2009.tb01013.x

[6] Daly, S. R., Mosyjowski, E. A., \& Seifert, C. M. (2014). Teaching creativity in engineering courses. Journal of Engineering Education, 103(3), 417-449. doi:10.1002/jee.20048

[7] Atwood, S. A., \& Pretz, J. E. (2016). Creativity as a factor in persistence and academic achievement of engineering undergraduates. Journal of Engineering Education, 105(4), 540-559. doi:10.1002/jee.20130

[8] Kell, H. J., Lubinski, D., Benbow, C. P., \& Steiger, J. H. (2013). Creativity and technical innovation: Spatial ability's unique role. Psychological Science, 24(9), 1831-1836. doi:10.1177/0956797613478615

[9] Sorby, S. A. (2007). Developing 3D spatial skills for engineering students. Australasian Journal of Engineering Education, 13(1), 1-11. doi:10.1080/22054952.2007.11463998

[10] Sorby, S. (2009). Developing spatial cognitive skills among middle school students. Cognitive Processing, 10 Suppl 2(S2), S312-315. doi:10.1007/s10339-009-0310-y

[11]Zappe, S.E., Reeves, P., Mena, I.B., \& Litzinger, T. (2015). A cross-sectional study of engineering students' creative self-concepts: An exploration of CSE, personal identity, and expectations. ASEE Annual Conference and Exposition, Conference Proceedings. 122.

[12] Jones, B. D., Ruff, C., \& Paretti, M. C. (2013). The impact of engineering identification and stereotypes on undergraduate women's achievement and persistence in engineering. Social Psychology of Education: An International Journal, 16(3), 471-493. doi:http://dx.doi.org.ezproxy2.library.drexel.edu/10.1007/s11218-0139222-x

[13] Bureau of Labor Statistics (BLS): Occupational Outlook Handbook. (2020). Retrieved from https://www.bls.gov/ooh/architecture-and-engineering/home.htm

[14] Khan, B., Robbins, C., \& Okrent, A. (2020). The state of science and engineering 2020. National Center for Engineering and Science Statistics (NCESS). Alexandria, VA. Retrived from https://ncses.nsf.gov/pubs/nsb20201 
[15] Beede, D. N., United States. Economics and Statistics Administration, United States. Economical and Statistics Administration, \& United States. Department of Commerce. Economics and Statistics Administration. (2011). Women in STEM: A gender gap to innovation. Washington, DC: U.S. Department of Commerce, Economics and Statistics Administration.

[16] National Center for Science and Engineering Statistics Directorate for Social, Behavioral and Economic Sciences (NCSES): National Science Foundation (NSF). (2019). Women, minorities, and persons with disabilities in science and engineering. Retrieved from: https://nCSEI.nsf.gov/pubs/nsf19304/digest

[17] Noonan, R. Office of the Chief Economist, Economics and Statistics Administration, U.S. Department of Commerce. (November 13, 2017). Women in STEM: 2017 update (ESA Issue Brief \#06-17). Retrieved from https://www.esa.gov/reports/women-stem-2017-update

[18] Hill, C., Corbett, C., St. Rose. A., \& American Association of University Women (AAUW). (2010). Why so few?: Women in science, technology, engineering, and mathematics. Washington, D.C: AAUW.

[19] Ohland, M. W., Brawner, C. E., Camacho, M. M., Layton, R. A., Long, R. A., Lord, S. M., \& Wasburn, M. H. (2011). Race, gender, and measures of success in engineering education. Journal of Engineering Education, 100(2), 225-252. doi:10.1002/j.2168-9830.2011.tb00012.x

[20] Scott, G., Leritz, L.E., \& Mumford, M.D. (2004). The effectiveness of creativity training: A quantitative review. Creativity Research Journal, 16 (4), 361-388.

[21] Dahle, R., Jockers, L., Scott, A., \& Wilson, K. (2017b). Major in engineering, minor in art: A new approach to retaining females in engineering. 2017 IEEE Women in Engineering (WIE) Forum USA East. doi:10.1109/WIE.2017.8285604

[22] Amabile, T. M. (1983). The social psychology of creativity: A componential conceptualization. Journal of Personality and Social Psychology, 45(2), 357-376. doi:10.1037//0022-3514.45.2.357

[23] Tierney, P., \& Farmer, S. M. (2011). Creative self-efficacy development and creative performance over time. Journal of Applied Psychology, (96), 277-293.

[24] Beghetto, R. A. (2006). Creative self-efficacy: Correlates in middle and secondary students. Creativity Research Journal, 18(4), 447-457. doi:10.1207/s15326934crj1804_4

[25] Cooper, R. \& Heaverlo, C. (2013). Problem solving and creativity and design: What influence do they have on girls' interest in STEM subject areas? American Journal of Engineering Education. 4. 10.19030/ajee.v4i1.7856.

[26] Beghetto, R. A., Kaufman, J. C., \& Baxter, J. (2011). Answering the unexpected questions: Exploring the relationship between students' creative self-efficacy and teacher ratings of creativity. Psychology of Aesthetics, Creativity, and the Arts, 5(4), 342-349. doi:10.1037/a0022834

[27] Katz-Buonincontro, J., Davis, O., Aghayere, A., \& Rosen, D. (2016, February). An exploratory pilot study of student experience in creativity-infused engineering technology courses. Journal of Cognitive Education and Psychology, 15(1), Special issue on Creativity.

[28] Tierney, P., \& Farmer, S. M. (2002). Creative self-efficacy: Its potential antecedents and relationship to creative performance. The Academy of Management Journal, 45(6), 1137-1148. doi:10.2307/3069429

[29] Claro S, Paunesku D, Dweck CS. Growth mindset tempers the effects of poverty on academic achievement. Proceedings of the National Academy of Sciences of the United States of America. 2016 Aug;113(31):86648668. DOI: 10.1073/pnas.1608207113.

[30] DeCuir-Gunby, J. T., \& Schutz, P. A. (2017). Mixed methods designs: Frameworks for organizing your research methods. In Decuir-Gunby J. T., \& Schutz, P. A. (Ed). Developing a mixed methods proposal: A 
practical guide for beginning researchers (pp. 83-106). Thousand Oaks: SAGE Publications, Inc. doi:10.4135/9781483399980.n10

[31] Delahanty, C. (2020). Creative Self-Efficacy of Undergraduate Women Engineering Majors: A Mixed Methods Study (p. xvi, 188 pages) [Drexel University]. https://doi.org/10.17918/00000005 